\title{
Editorial
}

\section{A propósito de la pandemia del coviD-19 y el modelo sanitario en Colombia*}

\section{Sobre algunos impactos asociados con la pandemia del coviD-19}

Ante la irrupción de una pandemia como la del Covid-19, con la consiguiente estrategia de distanciamiento y confinamiento para el control del contagio social del virus, es clara la reproducción de un drástico recorte de los ingresos de los trabajadores que laboran por cuenta propia, de los informales y del denominado "rebusque", y de los trabajadores formales que resulten desempleados, entre otros, con el consecuente empobrecimiento exagerado de amplias capas de la población.

Dependiendo de las políticas públicas sociales de protección que adopte el Gobierno nacional y del ritmo de reactivación de la actividad productiva, la pobreza monetaria podría ascender aún más en el segundo semestre, bordeando niveles promedio del 40 al $45 \%$, sin descartar, incluso, del $55 \%$ en zonas rurales.

Ello también está asociado con un aumento sustancial del desempleo abierto, al punto que ya en junio podría haber superado un $25 \%$ en las 13 principales ciudades, lo que afectaría especialmente a las mujeres y a los jóvenes, por lo que mientras más demorada y lenta sea la reactivación productiva, no solo se podrá mantener, sino también agudizar aún más.

Y con un agravante: la desigualdad, ya de por sí muy elevada, se acentuaría a niveles todavía más inaceptables que los imperantes con anterioridad a la pandemia.

Por su parte, el producto interno bruto (PIB) per cápita en el año en curso podría presentar una baja de entre $-7,0$ y $-8,5 \%$, resultante de los impactos de la pandemia y de la baja en los precios internacionales del petróleo, y solo podría recuperarse, en el mejor de los casos, hacia finales del año 2023 y principios del 2024, para alcanzar apenas el nivel observado en 2019.

En consonancia, podría esperarse una "quiebra" de buen número de empresas, en especial de tamaño medio y pequeñas, y de micronegocios informales - generadores de empleo-, con la consecuente pérdida de capital productivo y de tejido social, si no contaran con un oportuno apoyo gubernamental para el pago de nómina y de arrendamiento, por ejemplo.

Así, entonces, el deterioro de la situación social y económica podría implicar un retroceso de cerca de una década y, en el peor de los casos, de hasta una y media en términos de reducción de la pobreza monetaria y de la desigualdad en ingresos en el país, que podría tomar cerca de dos quinquenios en recuperar.

A su turno, resalta la crisis develada del sistema sanitario, entre otros factores, con:

1. Un discutible grado de mercantilización y terciarización privatizadora en la prestación de servicios.

2. Una clara insuficiencia de instalaciones, equipamiento, personal médico y de enfermería, agravada por una inaceptable precariedad de las condiciones laborales del personal sanitario.

3. Una excesiva fragilidad del sistema público, agravado por una inaceptable desigualdad entre entes territoriales en varios de ellos, casi inexistente en términos prácticos-.

4. Una evidente ineficacia en la institucionalidad reguladora y en la fiscalización de la operación del sistema, con predominio de multiplicidad de empresas intermediarias, muchas de ellas con muy deficiente capacidad especializada.

5. Unos elevados e injustificados costos de transacción, en desmedro de recursos públicos y de una adecuada y oportuna atención a la población.

* Nota de la Editora: este escrito, con modificaciones autorizadas por el autor, es extraído fundamentalmente del reciente libro publicado por el autor: Colombia. Transformaciones estructurales en medio de un contexto internacional en transición. Bogotá: Ediciones Desde Abajo; 2020. El texto fue publicado en septiembre, pero escrito entre los meses de abril y julio. 
6. La reproducción de graves daños sociales, colectivos e individuales, resultantes de la inadecuada o nula prestación de servicios respecto a lo requerido por muchos de los enfermos, en particular de poblaciones pobres y vulnerables, mediante la utilización de muy diversos esquemas de organización entre personas naturales y empresas prestadoras de servicios - legales o incluso de "fachada" - y de estrategias y mecanismos de apropiación indebida de recursos públicos — con la configuración de redes de macrocorrupción y cooptación institucional—. ${ }^{\dagger}$

En consecuencia, la pandemia del Covid-19 evidenció, a la vez que agravó, las profundas fracturas e injusticias sociales existentes en el país y las falencias estructurales en los sistemas de prestación de servicios esenciales como la salud, por lo que el país se ve abocado a recuperar la más de una década perdida en términos sociales, así como a afrontar el desmonte de "bloqueos" estructurales que continúan impidiendo la construcción de una sociedad democrática, plural, justa e incluyente. Es en este contexto, precisamente, que se torna indispensable abordar un proceso de reconstrucción social y económica, desde una perspectiva de transformaciones estructurales que rebasan la atención de los impactos de la propia pandemia, con la seguridad de que, en la actualidad, está abierta una gran oportunidad para abordar tareas transformadoras nucleares de la sociedad colombiana, buena parte de las cuales han sido aplazadas desde tiempo atrás.

\section{El papel indelegable del Estado bajo un modelo posbenefactor}

La pandemia del COviD-19 ha develado, a nivel global, algunas de las falencias estructurales de un modelo de estado de bienestar debilitado y crecientemente mercantilizado/terciarizado /privatizado en la prestación de servicios sociales esenciales, como el de la salud y de la educación, y en la protección social, con la creciente importancia del lucro privado, incluso sin debida prevalencia de prioridades sociales fundamentales.

Ante las exigencias de adecuación del modelo de Estado a las nuevas realidades internacionales y domésticas, resulta necesario avanzar hacia la construcción de un modelo de Estado posbenefactor, ${ }^{\ddagger}$ bajo el propósito de superar las falencias estructurales del modelo estatal imperante en países como Colombia.

En este contexto, sobresale la defensa del papel indelegable y de la responsabilidad insustituible del Estado en la garantía de la provisión de servicios sociales indispensables, especialmente a los grupos de la población desfavorecidos, con sistemas públicos eficientes y estrictamente regulados/fiscalizados, y con una gestión mediante esquemas que no impliquen una inadecuada mercantilización/privatización/terciarización en la prestación de los mismos, debido a sus falencias, de cara a fallas de la competencia en el mercado y a situaciones de crisis como, por ejemplo, las de una pandemia en el caso de la salud.

Al fin de cuentas, aun en el Norte global pareciera indispensable lograr consensuar un pacto social para la transición hacia un modelo novedoso de estado de bienestar en consulta con los mandatos constitucionales y las realidades económicas, políticas, sociales y culturales del mundo de hoy, suficientemente innovador, a fin de evitar retrocesos inaceptables en términos de los progresos alcanzados hasta finales del siglo xx, particularmente en el caso de países desarrollados, como sociedades incluyentes, democráticas, con observancia del goce efectivo de derechos fundamentales y adecuada calidad de vida para la mayoría de sus poblaciones, y al mismo tiempo, promover un desarrollo sostenible socioecológicamente.

\section{Elementos estratégicos hacia un modelo posbenefactor en el caso del sistema sanitario}

En el caso del sistema de salud en Colombia, sobresale la presencia de un precario Estado social de derecho, producto de la subordinación de responsabilidades y prioridades sociales inalienables, como la atención de calidad, oportuna y pertinente de las poblaciones más vulnerables y desprotegidas sin capacidad de pago, ni de los territorios más atrasados y marginados del país. Ello se presenta en el marco de un sistema sanitario regido por la Ley 100 [3] y la Ley Estatutaria de Salud [4], y que fuera diseñado bajo condiciones macroeconómicas muy diferentes a las prevalecientes desde hace ya un tiempo -conducentes a déficit financieros estructurales muy onerosos para su superación con base en el presupuesto público, además de su dudosa rentabilidad social en el mediano plazo ante la muy cuestionable eficiencia del sistema en términos sanitarios, financieros y sociales-.

En tales circunstancias, resulta evidente la necesidad de replantear el modelo de terciarización mercantilizada de la gestión sanitaria adelantada bajo el marco de la Ley 100 y de la Ley Estatutaria de la Salud. Para ello, se debería implantar un novedoso esquema societal público que garantice el ejercicio eficaz y eficiente de una responsabilidad

$\dagger \quad$ Véase al respecto, entre otros, [1].

$+\quad$ Para mayor detalle, véase [2]

$6 \quad$ Universidad de Antioquia 
inalienable, en última instancia, del Estado, como es la de asegurar el goce efectivo, oportuno y pertinente del derecho a la salud de la población colombiana, especialmente de la más desfavorecida y en los territorios más atrasados del país. Esto podría lograrse con las modalidades de cooperación pública-comunal-privada más idóneas y eficaces, bajo un riguroso marco regulatorio y de supervisión/fiscalización público y ciudadano.

Bajo este propósito, se habrá de instaurar un sistema público de salud comprehensivo e incluyente social y territorialmente, que responda a las exigencias que impone la observancia efectiva del derecho a la salud como precepto constitucional. Esto requerirá una revisión rigurosa del modelo sanitario desarrollado bajo su égida desde los años noventa, que tome en debida consideración las muy graves falencias estructurales de que adolece, tanto de índole sanitaria como financiera y regulatoria, y que la pandemia del COviD-19 ha develado en su debida expresión.

Deberá, entonces, brindársele prioridad especial a la promoción de la salud y a la prestación preventiva de servicios de salud, con figuras como las de médico de familia con carácter universalista, especialmente tanto de los hogares pobres y vulnerables como de los territorios más aislados y atrasados, y reformarse, entre otros factores:

1. El esquema de intermediación, financiarización y prestación de servicios, que se lleva a cabo mediante un entramado de entidades como las empresas e instituciones prestadoras de servicios - de muy diversa idoneidad y especialización; incluso, con no poca frecuencia, con graves faltas de capacitación y hasta hay casos como empresas "fachada"-.

2. La normatividad y el aparato institucional regulador/supervisor/fiscalizador, para evitar los malgastos, las desviaciones y la apropiación indebida de recursos públicos, en detrimento de la calidad y la cobertura de los servicios de salud, y que han reproducido severos daños de índole individual, colectiva y social.

3. El marco laboral, con la imposición de condiciones dignas de trabajo para el personal sanitario en términos de formalidad, de salarios y prestaciones sociales, de equipamiento e instrumental especializados.

4. El modelo de financiación del sistema de salud.

Luis Jorge Garay Salamanca

Ingeniero industrial, economista e investigador social.

\section{Referencias}

1. Garay LJ, Salcedo-Albarán E, Álvarez D. Macro-corrupción y cooptación institucional en el departamento de Córdoba, Colombia. Bogotá: Laboratorio Latinoamericano de Probidad y Transparencia. Fedesarrollo; 2020.

2. Garay LJ. Una perspectiva de la transformación del papel del Estado a un estado de bienestar: ¿Preludio hacia un Estado postbenefactor? En: Garay LJ, Espitia JE, editores. Medidas sociales y económicas de emergencia ante la pandemia del CovID-19 en Colombia. Bogotá: Ediciones Desde Abajo; 2020a.

3. Colombia, Congreso de la República. Ley 100, por la cual se crea el sistema de seguridad social integral y se dictan otras disposiciones (1993 dic. 23).

4. Colombia, Congreso de la República. Ley Estatutaria 1751, por medio de la cual se regula el derecho fundamental a la salud y se dictan otras disposiciones. (2015 feb. 16). 